\section{Paternal age and risk for schizophrenia}

\author{
STANLEY ZAMMIT, PETER ALLEBECK, CHRISTINA DALMAN, \\ INGVAR LUNDBERG, TOMAS HEMMINGSON, MICHAEL J. OWEN \\ and GLYN LEWIS
}

The first reported association between paternal age and schizophrenia was in 1958 (Johanson, 1958), a finding replicated by a number of other studies since then (Gregory, 1959; Hare \& Moran, 1979; Kinnell, 1983; Raschka, 1998). All of these studies have been case-control designs, using general population statistics for control comparisons. Although the findings have been reasonably consistent, the use of control groups that are probably not wholly representative of the cases means that selection bias is a possible explanation for the association (Bertranpetit \& Fananas, 1993). For example, cases may have been more likely to be recruited from urban areas than general population controls, which could be important given that paternal age is different in urban compared with rural areas. Bertranpetit \& Fananas used controls drawn from the same population as the cases, matched for age, gender, place of birth, employment and neighbourhood, and failed to find any association between paternal age and schizophrenia (Bertranpetit \& Fananas, 1993). Although a few other studies also have failed to find an association (Granville-Grossman, 1966; Costello et al, 1968; Gillberg, 1982), inefficient statistical tests (see Moran, 1968) and small sample sizes are likely to have contributed to these negative findings.

More recently, an association between paternal age and schizophrenia has been reported in an Israeli population-based birth cohort (Malaspina et al, 2001). This was the first cohort study to investigate this association and it overcame many of the problems related to study design that affected previous studies. However, it was unable to adjust for personality traits, which may be an important confounder in the relationship between schizophrenia and paternal age.

Two studies since then have reported a marginally significant association but, again, they were unable to adjust for the effects of personality (Brown et al, 2002;
Dalman \& Allebeck, 2002). In this study we examine the relationship between paternal age and schizophrenia, using data from a Swedish cohort of 50087 men with a 27-year record linkage follow-up, while controlling for a number of confounders, including personality traits relating to social integration of the subjects.

\section{METHOD}

\section{Subjects}

The cohort consisted of 50087 men conscripted into the Swedish army during 1969-1970. Over 98\% were 18-20 years of age. Only $2-3 \%$ of the male population were excused conscription on account of severe mental or physical disability, therefore selection as well as information bias are unlikely. Assessment at conscription included tests of IQ and self-administered questionnaires on family, social background, behaviour during adolescence and substance use. Only $3 \%$ of the sample had missing data for one or more of the self-reported questions, and less than $6 \%$ had missing data on paternal age.

All subjects underwent a structured interview conducted by a psychologist and those reporting any psychiatric symptoms were interviewed by a psychiatrist and given a diagnosis according to ICD-8 (World Health Organization, 1974) where applicable. All subjects have been made anonymous, and permission to use the database was granted by the Karolinska Institute Research Ethics Committee and the Swedish Data Inspection Board. Thirty-four cases of psychosis diagnosed at conscription were excluded from the study. Parental age at birth of subjects was obtained from the Statistics of Sweden Registers, blind to diagnosis.

\section{Follow-up}

The Swedish National Hospital Discharge Register recorded about $70 \%$ of all psychiatric admissions in 1970 , rising to $83 \%$ in 1973. Coverage was $97 \%$ from 1974 until 1983, 80-95\% between 1984 and 1986 and has been virtually complete since 1987. The linkage reported here was from 1970 until 1996 and covers the period of greatest risk of schizophrenia for men (ages 18-45 years). The incomplete registration during some periods is unlikely to have affected the results in any way. Patients were given clinical diagnoses according to the Nordic version of ICD-8 (ICD-9 from 
1987). Swedish psychiatrists tend to use a narrow definition of schizophrenia (Jablensky, 1986) and show good agreement with DSM-III criteria (Kristjansson et al, 1987). In addition, over $90 \%$ of people with schizophrenia are admitted to hospital at some point over a 10-year period (Geddes \& Kendell, 1995), and outcome misclassification is therefore likely to be low. Outcomes investigated were schizophrenia (codes 295.00-295.99) and other psychoses (including alcoholic, affective, drug-induced and paranoid psychoses).

\section{Analysis}

Logistic regression was used to calculate odds ratios and $95 \%$ confidence intervals for schizophrenia when given the paternal age, both before and after adjustment for tests were used to compare different models.

Personality variables concerned with interpersonal relationships, IQ score, place of upbringing, cannabis use and maternal age have been found to be associated with schizophrenia (Andreasson et al, 1987; Lewis et al, 1992; David et al, 1997; Malmberg et al, 1998; Zammit et al, 2002) potential confounders. Likelihood ratio

and were associated with paternal age in this cohort. These were included in the regression models, although some of these variables could lie along the causal pathway between paternal age and schizophrenia rather than confound the relationship. Nevertheless, investigation of these within the models could give important insights into the pathways involved in any association.

For the investigation that paternal age may have a stronger effect in sporadic rather than familial cases of schizophrenia, the familial cases were defined as subjects who had a family history of any mental health problems requiring treatment with psychotropic medication. For the purposes of analysis, paternal age was subdivided $a$ priori into five categories (ages 15-24, $25-34,35-44,45-54$ and $\geqslant 55$ years) because a linear effect of paternal age was unlikely, given the prior knowledge regarding accumulation of paternal germ cell mutations (Crow, 1997).

\section{RESULTS}

Of the 50053 subjects included in the analysis ( 34 subjects were excluded as they had

Table I Summary of confounders according to paternal age categories including number (and percentage) of subjects

\begin{tabular}{lccrr}
\hline $\begin{array}{l}\text { Paternal age } \\
\text { (years) }\end{array}$ & $\begin{array}{l}\text { Poor social } \\
\text { integration }\end{array}$ & Low IQ score & Drug use & Brought up in city \\
\hline $15-24$ & $116(2.0)$ & $616(10)$ & $870(15)$ & $1261(21)$ \\
$25-34$ & $522(2.2)$ & $2114(8)$ & $2871(12)$ & $5459(22)$ \\
$35-44$ & $343(2.7)$ & $1302(10)$ & $1328(11)$ & $2336(18)$ \\
$45-54$ & $68(3.0)$ & $269(11)$ & $214(10)$ & $326(14)$ \\
$\geqslant 55$ & $2(1.2)$ & $29(16)$ & $11(7)$ & $27(15)$ \\
\hline
\end{tabular}

a psychotic illness at the time of conscription), $362(0.7 \%, 95 \%$ CI $0.65-0.80 \%)$ were diagnosed as having schizophrenia by 1996 . Data on paternal age were missing on $25(6.9 \%)$ of those developing schizophrenia and on $2768(5.6 \%)$ of controls $\left(\chi^{2}=1.3\right.$, d.f. $\left.=1, P=0.27\right)$. For subjects with schizophrenia, paternal age ranged from 19 to 65 years $($ mean $=33.5$, s.d. $=7.7)$, whereas for controls the paternal age ranged from 15 to 75 years (mean $=32.2$, s.d.=7.0)

A summary of the potential confounders in relation to paternal age is presented in Table 1. For the purposes of this table only, poor social integration and IQ score were treated as dichotomous variables using the 10th percentile as a cut-off point for coding.

The crude and adjusted odds ratios (ORs) with $95 \%$ confidence intervals for developing schizophrenia when given the paternal age are presented in Table 2 . The crude odds ratio for schizophrenia when given a linear trend of paternal age was highly significant (crude OR for linear trend across age categories $=1.3,95 \% \mathrm{CI}$ $1.1-1.5, P<0.001)$, and this association persisted after adjustment for confounders (adjusted OR for linear trend $=1.3,95 \%$ CI $1.0-1.5, P<0.02)$. As a sensitivity analysis we excluded the oldest age category ( $\geqslant 55$ years), which resulted in an adjusted odds ratio for a linear trend of 1.2 (95\% CI $1.0-1.5, P=0.04)$.

A non-linear (within a logistic model) relationship between paternal age and risk of schizophrenia was investigated by inclusion of a quadratic term, but there was no evidence that this fitted the model better than a linear relationship (likelihood ratio test: $\chi^{2}=0.1$, d.f. $\left.=1, P=0.64\right)$. The

Table 2 Crude and adjusted odds ratios (OR) with $95 \%$ confidence intervals $(95 \% \mathrm{Cl})$ for developing schizophrenia and other psychoses according to paternal age

\begin{tabular}{|c|c|c|c|c|c|c|c|}
\hline \multirow{2}{*}{$\begin{array}{l}\text { Paternal age } \\
\text { (years) }\end{array}$} & \multirow[t]{2}{*}{ No. in cohort } & \multicolumn{3}{|c|}{ Schizophrenia } & \multicolumn{3}{|c|}{ Other psychoses } \\
\hline & & $\begin{array}{c}\text { No. of cases } \\
\text { (\%) }\end{array}$ & $\begin{array}{c}\text { Crude OR } \\
(95 \% \mathrm{Cl})\end{array}$ & $\begin{array}{c}\text { Adjusted OR } \\
(95 \% \mathrm{Cl})^{\prime}\end{array}$ & $\begin{array}{c}\text { No. of cases } \\
\text { (\%) }\end{array}$ & $\begin{array}{l}\text { Crude OR } \\
(95 \% \mathrm{Cl})\end{array}$ & $\begin{array}{l}\text { Adjusted OR } \\
\qquad(95 \% \mathrm{Cl})^{\prime}\end{array}$ \\
\hline $15-24$ & 6139 & $36(0.6)$ & $1.0^{2}$ & $1.0^{2}$ & $48(0.8)$ & $1.0^{2}$ & $1.0^{2}$ \\
\hline $25-34$ & 25159 & $157(0.6)$ & I.I (0.7-I.5) & $1.2(0.8-1.8)$ & $214(0.9)$ & I.I (0.8-I.5) & $1.2(0.8-1.6)$ \\
\hline $35-44$ & 13403 & II8 (0.9) & $1.5(1.0-2.2)$ & $1.6(1.0,2.6)$ & $119(0.9)$ & I.I (0.8-1.6) & I.I $(0.7,1.7)$ \\
\hline $45-54$ & 2405 & $22(0.9)$ & $1.6(0.9-2.7)$ & $1.6(0.8-3.1)$ & $28(1.2)$ & $1.5(0.9-2.4)$ & $1.3(0.7-2.3)$ \\
\hline$\geqslant 55$ & 187 & $4(2.2)$ & $3.8(1.3-10.7)$ & $3.8(1.3-11.8)$ & $3(1.7)$ & $2.1(0.7-6.8)$ & $1.7(0.5-5.8)$ \\
\hline Trend & & & $1.3(1.1-1.5)$ & $1.3(1.0-1.5)$ & & I.I (I.0-I.3) & I.I (0.9-I.3) \\
\hline
\end{tabular}

I. Adjusted for maternal age, drug use, IQ score, poor social integration and place of upbringing.

2. Baseline comparison. 
hypothesis that paternal age may have a stronger effect in sporadic cases rather than familial cases of schizophrenia (Malaspina et al, 2001) was investigated, but a likelihood ratio test failed to show evidence of any statistical interaction (likelihood ratio test: $\chi^{2}=9.8$, d.f. $=1, P=0.20$ ).

Although there was an association between maternal age and schizophrenia in the crude analysis (crude OR for linear trend across maternal age categories $=1.1$, $95 \%$ CI $1.0-1.2, \quad P=0.006)$, this disappeared after adjusting for paternal age (adjusted OR for linear trend $=1.0,95 \%$ CI 0.9-1.1, $P=0.90$ ).

We also investigated whether paternal age was associated with other (nonschizophrenia) psychoses $(n=446)$. There was no association between paternal age and other psychoses in the crude analysis (OR for linear trend $=1.1,95 \%$ CI 1.0 $1.3, P=0.09$ ) and this did not change after adjustment for confounders (adjusted $\mathrm{OR}=1.1,95 \%$ CI $0.9-1.3, P=0.46$ ).

\section{DISCUSSION}

\section{Mutation hypothesis}

Two main theories have been proposed to explain the association between advancing paternal age and schizophrenia. First, an increase in mutations arising in paternal germ cells with advancing age could increase the risk of schizophrenia. Such a mechanism has been implicated as underlying the increased paternal age in several autosomal dominant diseases, as well as diseases with more complex genetic aetiologies (Malaspina et al, 2001). The occurrence of new mutations in this way could help to explain the apparent maintenance of schizophrenia in the population in the face of reduced reproductive fitness (Book, 1953; Fananas \& Bertranpetit, 1995).

The persistence of an association with paternal age after adjustment for poor social integration, drug use and low IQ score, all of which are established risk factors for schizophrenia, suggests that these factors are not along the causal pathway. Therefore, if the germ cell mutation hypothesis is correct, advancing paternal age must affect the susceptibility to schizophrenia by other means, perhaps by a more direct influence on cerebral function.

Observations suggest that the accumulation of germ cell mutations is likely to be non-linear and probably exponential in nature (Crow, 1997). The increase in odds ratios for schizophrenia with advancing paternal age was non-linear in this study (an exponential increase in risk with advancing paternal age is equivalent to a linear relationship within a logistic model). Although it has been suggested that paternal age may have a stronger effect in sporadic cases rather than familial cases of schizophrenia if point mutations accumulate with advancing age (Malaspina et al, 2001), we found no evidence of any interaction between family history of psychiatric disease and paternal age on risk of schizophrenia, although tests for interactions tend to lack power.

The population-attributable fraction of schizophrenia for this sample that is due to having a father aged $>45$ years at birth is approximately $13 \%$. However, mean paternal age has increased over the past 20 years (Office for National Statistics, 2001), suggesting that this may be an underestimate of the true populationattributable fraction resulting from advanced paternal age. This may have important consequences for genetic studies, because recent mutations are much less amenable to detection by approaches that rely upon linkage disequilibrium with marker loci. The involvement of such mutations in conferring susceptibility can be detected only by direct association methods (Owen et al, 2000). Moreover, the inclusion of subjects who have older fathers in linkage disequilibrium studies will enrich for more recent mutations and, consequently, the power of linkage disequilibrium methods to identify susceptibility genes for schizophrenia may be reduced.

\section{Confounding by personality}

A second explanation for the association observed is that it is due to confounding. If older fathers have personality traits that are known to be associated with schizophrenia (such as schizoid or schizotypal traits), then these traits are likely to be shared by their offspring as a result of both heredity and upbringing (Coolidge et al, 2001). Such traits could result in an increased risk of developing schizophrenia in the offspring, and also in a later age of parenthood in the father as a result of a reduced ability for social integration (Granville-Grossman, 1966; Hare \& Moran, 1979).

A further study by Malaspina et al found that paternal age was more likely to be advanced in sporadic cases of schizophrenia compared with those with a family history of psychosis (Malaspina et al, 2002). This suggests that family history and paternal age may be acting as independent risk factors for this disorder. Although it is possible to interpret this as evidence against confounding by personality, family history of psychosis is unlikely to be a strong marker for personality traits that predispose towards delayed parenthood.

In our analyses, adjusting for poor social integration in the conscripts reduced the odds ratio for schizophrenia only minimally, suggesting that personality traits relating to social integration do not play a substantial role in explaining the association between paternal age and schizophrenia. The absence of direct information on paternal personality means that some residual confounding is very likely and cannot be excluded as an explanation for the association. However, we would expect that if a strong effect of personality existed then this would be evident in the measures of personality in the subjects themselves.

In conclusion, our result of an association between advancing paternal age and schizophrenia was not affected by adjusting for social integration of the subjects. This supports the hypothesis that accumulating germ cell mutations may lead to an increase in genetic liability to schizophrenia in the offspring.

\section{ACKNOWLEDGEMENTS}

This research is funded from a Clinical Training Fellowship grant awarded to S.Z. by the Medical Research Council UK (grant no. G84/5689). We also thank Jonas Sadigh for assistance with data management.

\section{REFERENCES}

Andreasson, S., Allebeck, P., Engstrom, A., et al (1987) Cannabis and schizophrenia. A longitudinal study of Swedish conscripts. Lancet, ii, 1483-1486.

Bertranpetit, J. \& Fananas, L. (1993) Parental age in schizophrenia in a case-controlled study (letter). British Journal of Psychiatry, 162, 574.

Book, J. A. (1953) Schizophrenia as a gene mutation. Acta Genetica, 4, 133-139.

Brown, A. S., Schaefer, C. A., Wyatt, R. J., et al (2002) Paternal age and risk of schizophrenia in adult offspring. American Journal of Psychiatry, 159, 1528-1533. Coolidge, F. L., Thede, L. L. \& Jang, K. L. (200I) Heritability of personality disorders in childhood: a preliminary investigation. Journal of Personality Disorders, 15, 33-40.

Costello, A. J., Gunn, J. C. \& Dominian, J. (1968) Aetiological factors in young schizophrenic men. British Journal of Psychiatry, II4, 433-44I. 
Crow, J. F. (1997) The high spontaneous mutation rate: is it a health risk? Proceedings of the National Academy of Sciences, USA, 94, 8380-8386.

Dalman, C. \& Allebeck, P. (2002) Paternal age and schizophrenia: further support for an association. American Journal of Psychiatry, 159, 1591-1592.

David, A. S., Malmberg, A., Brandt, L., et al (1997) IQ and risk for schizophrenia: a population-based cohort study. Psychological Medicine, 27, I3II-1323.

Fananas, L. \& Bertranpetit, J. (1995) Reproductive rates in families of schizophrenic patients in a casecontrol study. Acta Psychiatrica Scandinavica, 91, 202-204

Geddes, J. R. \& Kendell, R. E. (1995) Schizophrenic subjects with no history of admission to hospital. Psychological Medicine, 25, 859-868.

Gillberg, C. (1982) Parental age in child psychiatric clini attenders. Acta Psychiatrica Scandinavica, 66, 47I-478.

Granville-Grossman, K. L. (1966) Parental age and schizophrenia. British Journal of Psychiatry, II2, 899-905.

Gregory, I. (1959) An analysis of family data on 1000 patients admitted to a Canadian mental hospital. Acto Genetica, 9, 54-96.

Hare, E. H. \& Moran, P. A. (1979) Raised parental age in psychiatric patients: evidence for the constitutional hypothesis. British Journal of Psychiatry, 134, 169-177.

Jablensky, A. (1986) Epidemiology of schizophrenia: a European perspective. Schizophrenia Bulletin, 12, 52-73.

Johanson, E. (1958) A study of schizophrenia in the male. Acta Psychiatrica et Neurologica Scandinavica, 33

Kinnell, H. G. (1983) Parental age in schizophrenia (letter). British Journal of Psychiatry, 142, 204

Kristjansson, E., Allebeck, P. \& Wistedt, B. (1987)

Validity of the diagnosis of schizophrenia in a psychiatric inpatient register. Nordisk Psychiatrisk Tidskrift, 4I, 229-234.

Lewis, G., David, A., Andreasson, S., et al (1992) Schizophrenia and city life. Lancet, 340, 137-140.

Malaspina, D., Harlap, S., Fennig, S., et al (200I) Advancing paternal age and the risk of schizophrenia. Archives of General Psychiatry, 58, 36I-367.

_ , Corcoran, C., Fahim, C., et al (2002) Paternal age and sporadic schizophrenia: evidence for de novo mutations. American Journal of Medicine and Genetics, II4, 299-303.

Malmberg, A., Lewis, G., David, A., et al (1998) Premorbid adjustment and personality in people with schizophrenia. British Journal of Psychiatry, 172, 308-313.

\section{CLINICAL IMPLICATIONS}

- Paternity at advanced age increases the risk of schizophrenia in the offspring.

- Inclusion of subjects who have older fathers in studies that rely upon linkage disequilibrium may reduce the statistical power of such approaches.

\section{LIMITATIONS}

- These findings may not be applicable to women because only men were included in this study.

- Because the record linkage was for hospital admissions, it may be that some subjects with schizophrenia were not included as cases.

Because direct measurements of personality traits in the fathers were not available, some residual confounding is likely.

STANLEY ZAMMIT, MRCPsych, Department of Psychological Medicine, University of Wales College of Medicine, Cardiff, UK; PETER ALLEBECK, MD, Department of Social Medicine, Gothenburg University, Sweden: CHRISTINA DALMAN, MD, Psychiatric Epidemiology, Stockholm Centre of Public Health, Sweden; INGVAR LUNDBERG, MD, TOMAS HEMMINGSON, PhD, Department of Public Health Sciences, Karolinska Institute, Stockholm, Sweden; MICHAEL J. OWEN, FRCPsych, Department of Psychological Medicine, University of Wales College of Medicine, Cardiff, UK; GLYN LEWIS, PhD, Division of Psychiatry, University of Bristol, Bristol, UK

Correspondence: Dr S.G. Zammit, Department of Psychological Medicine, University Hospital of Wales, Cardiff CFI4 4XN, UK. Tel: +44 (0)2920 743058; fax: +44 (0)2920 746595; e-mail: zammits@cardiff.ac.uk

(First received 26 September 2002, final revision 4 June 2003, accepted 19 June 2003)

Moran, P. A. (1968) Maternal age and parental loss. British Journal of Psychiatry, II4, 207-214.

Office for National Statistics (200I) Birth Statistics: Review of the Registrar General on Births and Family Building Patterns in England and Wales - FMI. London: $\mathrm{HMSO}$

Owen, M. J., Cardno, A. G. \& O'Donovan, M. C. (2000) Psychiatric genetics: back to the future. Molecular Psychiatry, 5, 22-31.
Raschka, L. B. (1998) Parental age and schizophrenia. Magyar Andrologia, 3, 47-50.

World Health Organization (1974) Glossary of Mental Disorders and Guide to their Classification, for Use in Conjunction with the International Classification of Diseases (8th edn). Geneva: WHO.

Zammit, S., Allebeck, P., Andreasson, S., et al (2002) Self-reported cannabis use as a risk factor for schizophrenia: further analysis of the 1969 Swedish conscript cohort. BM], 325, ||199-|20I. 